\title{
Optimal Concentration of Calcium and Electric Field Levels Improve Tetraploid Embryo Production by Electrofusion in Mice
}

\author{
Lun SUO ${ }^{1 *}$, Fen WANG ${ }^{1 *}$, Guang-Bin ZHOU ${ }^{2,3)}$, Jian-Min SHI'), Yong-Bin WANG'), \\ Shen-Ming ZENG'), Jian-Hui TIAN ${ }^{1}$, , Shi-En ZHU $^{1,2)}$ and Guo-Shi LIU ${ }^{1,2)}$ \\ ${ }^{1)}$ Laboratory of Animal Embryonic Biotechnology, College of Animal Science and Technology, China Agricultural \\ University, Beijing 100193, ${ }^{2}$ State Key Laboratories for Agrobiotechnology, China Agricultural University, Beijing 100193 \\ and ${ }^{3)}$ Dujiangyan Campus of Sichuan Agricultural University, Dujiangyan 611830, China
}

Abstract. Polyploid embryo production is an important technique in generating mice directly from embryonic stem (ES) cells. The present study was designed to assess the effect of different calcium concentrations and electric field intensities on the production of tetraploid embryos with higher developmental potential by electrofusion. Two-cell mouse embryos were electrofused in fusion solution containing different concentrations of calcium ion $(0.05,0.1,0.2$, $0.4,0.6,0.8,1.0,1.2$ and $1.4 \mathrm{mM}$ ). The rates of blastomere fusion, and subsequent cleavage and development of tetraploids to the blastocyst stage were highest when two-cell embryos were electrically stimulated in a fusion medium containing $1.0 \mathrm{mM}$ calcium. Therefore, we tested electric field intensities $(0.6,0.8,1.0,1.2 \mathrm{and} 1.4 \mathrm{kV} / \mathrm{cm})$ for electrofusion of two-cell embryos and subsequent development to the blastocyst stage in $1.0 \mathrm{mM}$ calcium. The highest rates of fusion and blastocyst formation were observed when the electric field strength was $0.8 \mathrm{kV} / \mathrm{cm}$. The present results showed that mouse two-cell embryos stimulated with $0.8 \mathrm{kV} / \mathrm{cm}$ in a fusion medium containing $1.0 \mathrm{mM}$ calcium had the highest rates of fusion and development to the blastocyst stage.

Key words: Calcium concentrations, Electric field, Electrofusion, Tetraploid embryo, Mice

(J. Reprod. Dev. 55: 383-385, 2009)

$\mathbf{T}$ he polyploid mammals are not viable under natural conditions because polyploid embryos usually cannot survive the early developmental stage. However, as a research tool, polyploidy embryos have been widely applied to compensate for embryonic lethality as a result of defective extraembryonic phenotypes in laboratory mice, as well as a method of generating mice directly from ES cells [1-3].

Up to now, two methods, 1) cell cleavage inhibition using colchicines [4] or cytochalasin B [5] and 2) cell fusion by polyethylene glycol [6, 7], inactivated Sendai virus [8] or electrofusion [9, 10], have been established for generation of tetraploid embryos. It has been reported that the method of cleavage inhibition may produce several tetraploid:diploid $(4 n: 2 n)$ mosaics rather than homogeneously tetraploid animals [11]. A possible reason for this could be that while the first cleavage is successfully inhibited, sister blastomeres escape inhibition and divide into two "normal" diploid blastomeres, thus creating a three-cell mosaic. The electrofusion procedure, however, is considered to be robust and has been successfully applied to generation of tetraploid embryos in a number of other species such as the rabbit [12], pig [13] and cow [14, 15].

During electrofusion, the plasma membrane is disrupted by a voltage difference across it, which is related to the calcium concentration in the fusion solution [16, 17] and the electrical field parameters [18]. The electric field intensity is an important factor that affects the efficiency of electrofusion, which has been

Accepted for publication: March 15, 2009

Published online in J-STAGE: May 14, 2009

Correspondence: G-S Liu (e-mail: gshliu@cau.edu.cn) \& S-E Zhu (e-mail:

zhushien@cau.edu.cn)

* These authors contributed equally to this work. researched intensively previously [19]. However, there are few reports about the effect of the calcium concentration and electric field intensity on production of tetraploid embryos, which is very important for generation of mice directly from ES cells.

We optimized the calcium concentration and electric field intensity to improve the efficiency of tetraploid embryo production. This provides the basis for a high efficiency tetraploid embryo production system with better developmental potential in mice.

\section{Materials and methods}

\section{Reagents}

All chemicals and media were purchased from Sigma Chemical (St. Louis, MO, USA), unless otherwise indicated.

\section{Embryo collection}

Female mice at 6-8 weeks of age were maintained at 20-22 C under a 14-h (0600-2000 h) light and 10-h (2000-0600 h) dark schedule and induced to superovulate by i.p. injection of $10 \mathrm{IU}$ of pregnant mare serum gonadotrophin (PMSG, Ningbo Hormone Products, Ningbo city, PR China) followed by 10 IU of hCG $48 \mathrm{~h}$ later (Ningbo Hormone Products). They were then mated with 8to 10 -week-old white, male Kunming mice and examined for vaginal plugs the next morning.The mice with a vaginal plug were sacrified, and two-cell embryos were collected by flushing their oviducts with M2 medium 44-46 h post hCG.

\section{Electrofusion and in vitro culture of fused embryos}

Before electrofusion, two-cell embryos in each group were equilibrated in fusion solution, $300 \mathrm{mM}$ mannitol solution supple- 


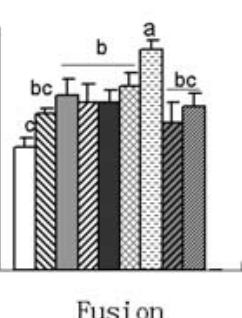

Fusion

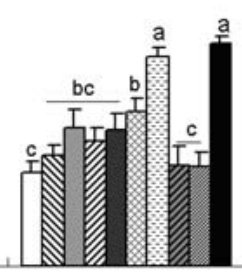

Cleavege

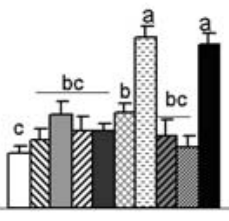

Blastocyst

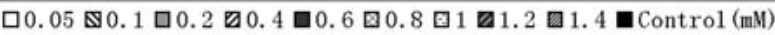

Fig. 1. Effects of calcium concentration on fusion and subsequent development of embryos. Different letters above the columns indicate significant differences $(\mathrm{P}<0.05)$. The numbers of embryos used in the $0.05,0.1,0.2,0.4,0.6,0.8,1.0,1.2,1.4 \mathrm{mM}$ and control groups were 180, 220, 176, 180, 160, 176, 164, 168, 168 and 152, respectively.

mented with $0.1 \mathrm{mM} \mathrm{MgSO}_{4}$ and different concentrations (0.05, $0.1,0.2,0.4,0.6,0.8,1.0,1.2$ and $1.4 \mathrm{mM}$ ) of $\mathrm{CaCl}_{2}$ for about 1 min. These embryos were then put into fusion solution between the electrodes, with the cleavage plane parallel to the electrodes, and stimuated with two DC pulses at $1.0 \mathrm{kV} / \mathrm{cm}$ for $40 \mu \mathrm{sec}$. After the 'optimal calcium concentration' was determined, fusion of two-cell embryos under different electric field levels (0.6, 0.8, 1.0, 1.2 and $1.4 \mathrm{kV} / \mathrm{cm}$ ) was assessed using the determined concentration. After stimulation, the embryos were washed 3 times in human tubal fluid (HTF) medium and cultured in this medium at $37 \mathrm{C}$ in an atmosphere of $5 \% \mathrm{CO}_{2}$ in air. Thirty minutes later, the membrane fusion status was assessed, and two blastomeres having a continuous plasma membrane were recognized as fused embryos. The fused embryos were then cultured in HTF medium and observed for development. Embryos that were not subjected to electrofusion were cultured as a control. All experiments mentioned above were repeated at least three times.

\section{Examination of cell numbers of blastocysts}

The embryos were fixed with 3.7\% paraformaldehyde for 30 min and then incubated in the dark at $37 \mathrm{C}$ in $\mathrm{M} 2$ medium $+10 \mu \mathrm{g} /$ $\mathrm{ml}$ Hoechst 33342 for $10 \mathrm{~min}$. Following extensive washing, the embryos were mounted on slides and examined using a microscope. Each group was repeated three times, and at least 21 embryos were treated in each group.

\section{Chromosome analysis}

The methods used for chromosome analysis were described in a previous study [20], with some modification. Briefly, the blastocysts produced from electrofusion were transferred to the HTF medium containing $0.5 \mu \mathrm{g} / \mathrm{ml}$ colchicine, cultured for $4-5 \mathrm{~h}$ and then put into $1 \%$ sodium citrate hypotonic solution at $4 \mathrm{C}$ for 20 min. These embryos were dropped on the slides and fixed with the stationary liquid (methanol: acetic acid=2:1) for 2-3 min. After staining with Hoechst 33342, these specimens were observed under a microscope for chromosome analysis. At least 17 embryos were treated in each group.

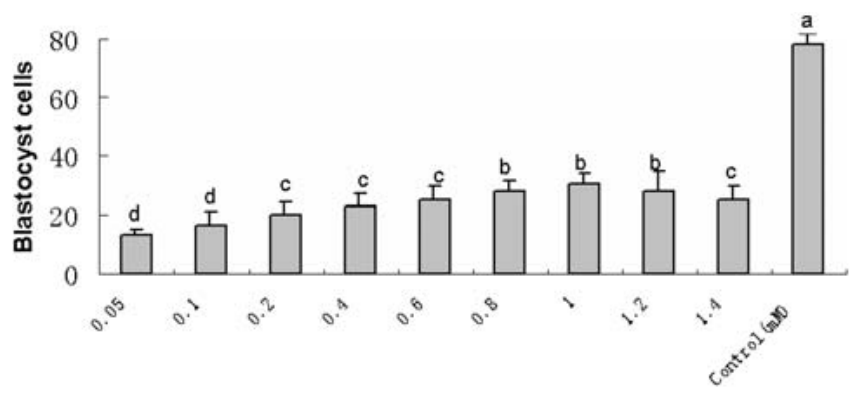

Fig. 2. Effect of calcium concentration on the blastocyst cells of tetraploid embryos. Different letters above the columns indicate significant differences $(\mathrm{P}<0.05)$. At least 21 embryos were assessed in each group. Moreover, the rate of tetraploid embryos in every group was $100 \%$.

\section{Statistical analysis}

Pairwise comparisons of all data in the present study were performed by one-way ANOVA with the Statistical Analysis System (SAS) software (SAS Institute, Cary, NC, USA). A P value of less than 0.05 was considered to be statistically significant.

\section{Results}

\section{Effects of calcium concentration on fusion and subsequent development of embryos}

When two-cell embryos were electrofused in a medium containing $1.0 \mathrm{mM}$ calcium, the proportions of fusion, and subsequent cleavage and development to the blastocyst stage of tetraploids were $91.18 \pm 3.32$, $86.18 \pm 3.60$ and $70.57 \pm 4.09$, respectively. The values were significantly higher than those after electorfusion in a medium containing the other concentration of calcium $(\mathrm{P}<0.05$; Fig.1).

\section{Effects of calcium concentration on tetraploid embryos production}

As shown in Fig.2, the number of cells per blastocyst was also highest when the fusion medium containing $1.0 \mathrm{mM}$ calcium was used. Furthermore, all examined blastocysts were tetraploid regardless of the calcium concentration of the fusion medium.

\section{Effects of electric field on the developmental potential of fused embryos}

As shown in Fig. 3, the rates of fusion (97.03\%), subsequent cleavage (75.2\%) and development to the blastocyst stage (60.2\%) were highest when two-cell embryos were fused by DC pulses at $0.8 \mathrm{kV} / \mathrm{cm}$ in fusion medium containing $1.0 \mathrm{mM}$ calcium. All rates were significantly lower in embryos that were fused at higher than $1.2 \mathrm{kV} / \mathrm{cm}$ than in those that were fused at lower than $0.8 \mathrm{kV} / \mathrm{cm}$ (P $<0.05$ ). There were no significant differences among the embryos fused by DC pulses between 0.6 and $1.0 \mathrm{kV} / \mathrm{cm}$ in terms of the rate of fusion and cleavage or among embryos fused by DC pulses between 0.6 to $1.2 \mathrm{kV} / \mathrm{cm}$ in terms of the rate of development to the blastocyst stage. 


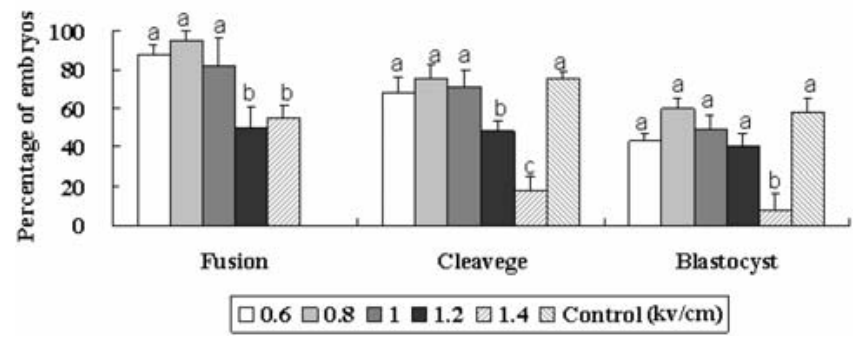

Fig. 3. Effect of intensity of electric field on the developmental potential of fused embryos. Different letters above the columns indicate significant differences $(\mathrm{P}<0.05)$. The numbers of embryos used in the $0.6,0.8,1.0,1.2,1.4 \mathrm{kV} / \mathrm{cm}$ and control groups were 104 , $107,117,122,136$ and 100 , respectively.

\section{Discussion}

The present study assessed the effect of different calcium concentrations and electric field levels on the production of tetraploid embryos by eletrofusion. The result showed that the rates of fusion, cleavage and development to the blastocyst stage were highest when two-cell embryos were electrostimulated by DC pulses at $0.8 \mathrm{kV} / \mathrm{cm}$ in a fusion medium containing $1.0 \mathrm{mM}$ calcium, although all examined blastocysts were tetraploid regardless of the calcium concentration of the fusion medium.

Previous studies had indicated that a higher calcium concentration could induce intracellular $\mathrm{Ca}^{2+}$ flux, which plays an important role in cell growth and differentiation [16, 21, 22]. In nuclear transfer in pigs, Cheong (2002) also indicated that the fusion rate and subsequent development of nuclear transfer embryos were notably improved when the fusion medium contained $1.0 \mathrm{mM}$ calcium compared with the case of $0.1 \mathrm{mM}$ calcium [16, 17]. Nevertheless, Collas (1993) proved that fusion solution that contained too much calcium could have a negative effect on the development of bovine embryos [23], which was also seen in the present study. Our results showed that the rate of fusion and subsequent development significantly decreased when the fusion solution contained 1.2 and 1.4 mM calcium.

Electric field intensity is an important factor that affects the efficiency of membrane fusion [19]. During the electrofusion procedure, the closely apposed lipid membranes of the two cells are disrupted by a voltage difference across the plasma membranes [24], which correlates closely with the electric field. A lower electric intensity might not have been sufficient enough to disrupt the membrane, possibly resulting in reduction of the fusion rate of the embryos. On the other hand, the cell membrane would be disrupted by a higher electric field intensity during the fusion process [25]. In the present study, the rates of fusion and development to the blastocyst stage were significantly higher in embryos that were treated with an electric field at $0.8 \mathrm{kV} / \mathrm{cm}$ than those treated with any other electric field intensity.

In summary, the present study shows that electrostimulation of mouse two-cell embryos under an electric field at $0.8 \mathrm{kV} / \mathrm{cm}$ in a fusion medium containing $1.0 \mathrm{mM}$ calcium is optimal for production of tetraploid embryos in mice.

\section{Acknowledgments}

The present work was supported by the Beijing Municipal Natural Science Foundation (5063044). We thank Dr. Qing gang Meng (Department of Animal, Dairy and Veterinary Sciences, Utah State University, Logan, UT 84322, USA) for critical review of this manuscript.

\section{References}

1. Nagy A, Gócza E, Diaz EM, Prideaux VR, Iványi E, Markkula M, Rossant J. Embryonic stem cells alone are able to support fetal development in the mouse. Development 1990; 110: 815-821.

2. Nagy A, Rossant J, Nagy R, Abramow-Newerly W, Roder JC. Derivation of completely cell culture-derived mice from early-passage embryonic stem cells. Proc Nat Acad Sci USA 1993; 90: 8424-8428.

3. Ishiguro N, Kano K, Yamamoto Y, Taniguchi K. Tetraploid cells of enhanced green fluorescent protein transgenic mice in tetraploid/diploid-chimeric embryos. J Reprod Dev 2005; 51: 567-572.

4. Edwards RG. Colchicine-induced heteroploidy in the mouse. II. The induction of tetraploidy and other types of heteroploidy. J Exp Zool 1958; 137: 349-362.

5. Snow MH. Tetraploid mouse embryos produced by cytochalasin B during cleavage. Nature 1973; 244: 513-515.

6. Eglitis MA. Formation of tetraploid mouse blastocysts following blastomere fusion with polyethylene glycol. J Exp Zool 1980; 213: 309-313.

7. Spindle A. Polyethylene glycol-induced fusion of two-cell mouse embryo blastomeres. Exp Cell Res 1981; 131: 465-470.

8. O'Neill GT, Speirs S, Kaufman MH. Sex-chromosome constitution of postimplantation tetraploid mouse embryos. Cytogenet Cell Genet 1990; 53: 191-195.

9. Kubiak JZ, Tarkowski AK. Electrofusion of mouse blastomeres. Exp Cell Res 1985, 157: 561-566.

10. Kaufman MH, Webb S. Postimplantation development of tetraploid mouse embryos produced by electrofusion. Development 1990; 110: 1121-1132

11. Tarkowski AK, Witkowska A, Opas J. Development of cytochalasin in B-induced tet raploid and diploid/tetraploid mosaic mouse embryos. J Embryol Exp Morphol 1977; 41: 47-64.

12. Ozil JP, Modlinski JA. Effects of electric field on fusion rate and survival of 2-cell rabbit embryos. J Embryol Exp Morphol 1986; 96: 211-228.

13. Prather RS, Hoffman KE, Schoenbeck RA, Stumpf TT, Li J. Characterization of DNA synthesis during the 2-cell stage and the production of tetraploid chimeric pig embryos. Mol Reprod Dev 1996; 45: 38-42.

14. Iwasaki S, Kono T, Fukatsu H, Nakahara T. Production of bovine tetraploid embryos by electrofusion and their developmental capability in vitro. Gamete Res 1989; 24: 261-267.

15. Curnow EC, Gunn IM, Trounson AO. Electrofusion of two-cell bovine embryos for the production of tetraploid blastocysts in vitro. Mol Reprod Dev 2000; 56: 372-377.

16. Cheong, HT, Park, KW, IM, GI-SUN, Lai L, Sun, QY, Day BN, Prather, RS. Effect of elevated $\mathrm{Ca}^{2+}$ concentration in fusion/activation medium on the fusion and development of porcine fetal fibroblast nuclear transfer embryos. Mol Reprod Dev 2002; 61 488-492.

17. Miyoshi K, Yuki Y, Yoshida M. Optimization of $\mathrm{Ca}^{2+}$ concentrations in fusion and activation media for production of cloned embryos from miniature pig somatic cells. J Reprod Dev 2005; 51: 699-706.

18. Rickords LF, White KL. Electrofusion-induced intracellular $\mathrm{Ca}^{2+}$ flux and its effect on murine oocyte activation. Mol Reprod Dev 1992; 31: 152-159.

19. Zimmermann U, Vienken J. Electric field induced cell-to-cell fusion. J Membr Biol 1982; 67: 165-182

20. Li GP, Cai SX, Xu LB, Sun XS, Liu ZH, Tan JH. Studies on the early development of mouse tetraploid embryos produced by electrofusion. Dev Reprod Biol 1998; 7: 17-23

21. Sun FZ, Hoyland J, Huang X, Mason W, Moor RM. A comparison of intracellular changes in porcine eggs after fertilization and electroactivation. Development 1992; 115: 974-956.

22. Komazaki S, Takano K. Induction of increase in intracellular calcium concentration of embryonic cells and acceleration of morphogenetic cell movements during amphibian gastrulation by a 50-Hz magnetic field. J Exp Zool Part A Ecol Genet Physiol 2007; 307 156-162.

23. Collas, P, Fissore R, Robl JM, Sullivan EJ, Barnes PL. Electically induced calcium elevation, activation and parthenogenetic development of bovine oocytes. Mol Reprod Dev 1993; 34: 212-223.

24. McLaughlin KJ. Production of tetraploid embryos by electrofusion. Methods Enzymol ogy 1993; 225: 919-929.

25. Cheong HT. Effect of various electric field on the fusion and in vitro development of mouse two cell embryos. Theriogenology 1991; 36: 875-885. 